\title{
LIFE IN SOUNDS, COLOURS AND ATMOSPHERES: A CASE STUDY ON SYNAESTHESIA
}

\begin{abstract}
In this article we focus on the world of colour associations and atmospheres experienced by a famous and successful piano pedagogue. The aim of the study is to open one point of view inside the phenomenon of synaesthesia through one case which is truly reliable. This case study is based on personal interviews with the pedagogue (August 16-19, 1999, and April 27, 2010), and the findings are anchored theoretically in the synaesthetic experience. The article subtitles are the themes and subjects used in the interviews, and the free association discussions have been shaped into more structured form. To express the events in a way that is similar to the real life experiences, we have quoted the interviewee directly in our text.

The article shows one individual's way of experiencing, seeing and feeling the world of sounds and voices. It is concluded that the synaesthesia experiences of the target of the case study were genuine and they were repeated in two different interviews. Synaesthesia is a real phenomenon and not fake in any point of view.
\end{abstract}

Keywords: case research; synaesthesia

\section{INTRODUCTION}

\section{Synaesthesia}

The etymological roots of the concept of synaesthesia are in the Greek language. "Syn" meaning "together, combining", joined to "aesthesis", meaning "sensation, finding, discovery", form a word. It means "combined sensation". For the person who experiences synaesthesia, the activation of one sense (for example, hearing) will activate another sense (for example, seeing), which may lead to an intense experience in that other sensory modality, as well (Barnett \& Newell, 2008; Barnett et al., 2008; Beeli et al., 2008; Cytowic, 1997; Cytowich, 2003; Ward et al., 2008; van Campen, 2010; Palolahti, 2007; Ramachandran \& Hubbard, 2003; Ward \& Mattingley, 2006). The phenomenon is not very common; according to Cytowic (Cytowic, 1995, 1997; Day, 1996; Cammack, 1999) synaesthesia is found in only one adult of every 25000 , and the percentage changes depending on how the phenomenon is defined.

A remarkable common element in different types of documented cases of synaesthesia is that the aptitude first occurs in early childhood; moreover, synaesthetes have been surprised when, as adults, they have realized that not all people have this ability. The phenomenon is much more common among children, and seems to have a tendency to disappear around the age of puberty. The reason is not known, but probably the hormonal changes taking place in the body plays some role.

In medical science the concept of synaesthesia has been discussed since the early 1700 . The first research in the area appeared between 1850 and 1930. During that time the phenomenon 
was researched, both from various scientific approaches as well as from artistic points of view (Palolahti, 2007), and a great deal of literature was published (Fecher, 1860; Galton, 1880; Mendoza, 1890; Argelender, 1927). Meanwhile artists contributed their share to the topic publishing poems, pamphlets and compositions (Baudelaire, 1860; Rimbaud, 1871; Kandinsky, 1911/1912; Skrjabin, 1910). In 1990 when the neurologist Richard Cytowic (1989/2002) published his research on the subject, a new era began in synaesthesia research. As cognition science took the place of behaviourism and new methods were introduced in the field of brain research, the research into synaesthesia grew more active, successful and promising (Palolahti, 2007).

\section{THE AIM OF THE STUDY}

To seek a point of view in the phenomenon of synaesthesia through a case study of a recognized and well-known Finnish music personality and pedagogy.

\section{MATERIALS AND METHODS}

This article offers a small blink into the world of a genuine synaesthetic person, and shows one way of experiencing the not so well-known phenomenon.

\section{What is genuine synaesthesia?}

The phenomenon of synaesthesia is difficult to address for many reasons. Synaesthesia is more common in childhood and more usual among women than among men (the scale is about 6:1), and many of those who experience synaesthesia are left-handed (Cytowic, 1989/2002; Ramachandran et al., 2001a, 2001b; Ramachandran \& Hubbard, 2006). Synaesthesia is also more common among musicians, writers and visual artists than among people working in other fields. A rather large proportion of synaesthetes, about $10 \%$, are homosexual. Those with synaesthesia also have more unexplained experiences, such as the phenomenon of déjà-vu, clairvoyance, memories of a time before birth, expansion of consciousness, out-of-body experiences and experiences of being abducted by UFOs, than the rest of the population (Cytowic, 1997). Because the phenomenon is quite rare, it has been difficult to research. The nature of the experience is also very personal and has often been unscientifically made mysterious by such artists as Wassily Kandinsky. Until the last few decades, a lack of objective scientific criteria and testing arrangements slowed the research on synaesthesia and contributed to underestimating the research of synaesthesia as well as researchers and synaesthetes. Although there are documents and research reports from a 300year time period, many researchers have neglected the topic. Considerable literature has been published on the nature of the phenomenon, its possible hereditary nature, its different variations and its documented cases, yet scepticism still shadows into its particulars (Palolahti, 2007).

These characteristics have slowed down synaesthesia research because both synaesthetes as well as synaesthesia researchers have been easily branded as mentally unbalanced or at least of questionable credibility. Synaesthesia has been seen as a kind of abnormality, but also as a way of nonverbal thinking (Galayev, 1999). Still, synaesthetes are mainly normal individuals, equipped with usual senses, well balanced mentally and often intelligent. Many of them have exceptionally good memories, as they connect many elements to a single word (such as a colour) which helps in memorization (Cytowic, 1997). The most common expression of synaesthesia is colour hearing, which means experiencing colours when hearing music or single tones or chords. A stimulus of the sense of hearing may cause visual experiences or the sense of feeling, smelling or tasting. Sometimes the experience is called intermodal phenomenon whereby two senses function together in different ways. The most common form of synaesthesia is colourhearing in which sound and colour mix. Synaesthesia has been explained, for example, through neurophysiology and cognition science and through culturally learned associations. Cytowich 
and Eagleman (2009) divide common synaesthesia types: number forms, coloured letters, tasted words, coloured hearing, and the personification of letters and numbers.

Two researchers from the United States, Vilayanur S. Ramachandran and Edward M. Hubbard (2005), have listed the most common doubts about the phenomenon of synaesthesia as follows:

1) People who claim to experience synaesthesia are simply crazy, and the whole phenomenon is the result of their hyperactive imaginations.

2) These people are trying to get attention from others by pretending to be different.

3) The phenomena classified as synaesthetic experiences are simply memories from childhood, for example, associative imaginary picture memories from the first primer books, colouring books, etc.

4) Often the talk about synaesthesia is confused and metaphorical nonsense without any scientific content.

5) A relatively common opinion is that synaesthetes are a group of drug users, potheads and acid junkies, who have ruined their brains. For example, LSD-users have often talked about synaesthetic experiences during and after their drug trips (Palolahti, 2007).

These criticisms clearly show the importance of finding criteria to identify authentic experiences of synaesthesia. This requires a scientific approach and strict analyses in order to distinguish genuine phenomena from other, perhaps similar psychological phenomena. Cytowic (1995; 1989/2002) has identified the five most important criteria for diagnosing genuine synaesthesia. They are:

1) The phenomenon is involuntary and cannot be regulated by a person's will. Still, focusing concentration on a certain aspect of the sensed incident may strengthen the experience and in this way vitalize it.

2) A visual synaesthetic experience typically has a spatial dimension. Visual synaesthetic associations and images are projected outside person's own head to close spatial vicinity. This means that the experiences cannot be products of a vivid visual imagination nor direct seeing.

3) Synaesthetic experiences are general by nature and remarkably consistent in time. Mostly, they remain similar throughout a whole lifetime. Their general nature means that synaesthetic experiences are not organized in the normal way; they are not strictly confirmed observations about objects in the environment, but rather raw disorganized sensed experiences. For example, in auditory-visual synaesthesia an auditory stimulus (such as music) causes parallel experiences that are usually described as rhythmically moving colours and different visual shapes that change every moment.

4) Synaesthesia experiences are usually re-enactable as are all other observational memories saved in the episodic memory. Synaesthetic persons have been observed to have better than average memories (Smilek \& Dixon, 2002; Smilek, Dixon,Cudahy \& Merikle, 2002). Sometimes parallel synaesthetic experiences have been easier to recall than the original sense experience.

5) Synaesthetic sense experience and emotions are often closely connected. Synaesthetic individuals are strongly convinced of the genuineness of their experiences, as these have been part of their lives since childhood. The systematic presence of emotional elements seems to implicate the limbic system in modulating the synaesthetic experience.

In 1993 Simon Baron-Cohen's research team succeeded in proving that the consistency 
of synaesthesia was $92.3 \%$ among synaesthetes and only $37.6 \%$ among the control group by using word-colour synaesthesia in which certain words caused certain colour association. The test was made two times and there was one year's time gap between the two tests. This showed that the consistency of synaesthesia is good. The same kinds of results have also been found in other research. Synaesthetic people seem to have some differences in brain function compared to others. For example, their reactions to colourful visual stimulus caused activation only in the right side of the cortex, while normally such stimulus activates bilaterally (Nunn et al., 2002). Some researchers have found clues indicating that the visual information process in the synaesthesia phenomenon is strongly automatic and based on preliminary knowledge (Hubbard \& Ramachandran, 2005; Gray et al., 2002). The scale of different types of synaesthesia widened in the last few decades as more research had been done (Cytowic, 1989/2002). The two most common types of synaesthesia appear to be the graphics-colour-type and the auditory-visualtype.

\section{About the interviewee}

The interviewee is an eccentric, successful Finnish piano pedagogue and performing artist who has lived most of his life in different towns in Finland. He has taught many successful artists and has himself been a performing artist, giving solo concerts. He has also worked in opera. The interviewee is very gifted in the field of languages; he speaks many languages. He has translated into Finnish and directed several opera productions. His Finnish language is extremely innovative and original, which makes translating its ideas into English quite challenging. The colourful expressions are difficult, even in Finnish. The interviewee is a highly sophisticated gentleman who can truly be called an aesthete, as his interest in all arts is obvious. The interview was made by one of the authors who earlier had been a piano student of the interviewee. This background helped to create a trusting and open atmosphere. The interviewee had read through the present article and accepted the text and its interpretations. The parts of the text in bold, are the interviewer's comments or questions.

\section{Single tunes have their atmospheres and colours. Certain tunes have warmth while others have frostiness or chillness.}

The tone $C$ ? It is nothing by itself, but I immediately connect it to $\mathrm{C}$-major or $\mathrm{C}$-minor. It has a certain paradox in its essence, and $\mathrm{C}$ may show up light as well as dark. $\mathrm{C}$ includes the whole musical cosmos. $C$ is not necessarily blue, green or red. It can never be in my world. Maybe we could jump to the conclusion that single tunes have not yet crystallized into colours? A chord produces a colour, but not a single tune or note. $\mathrm{C}$ is a sacred tone to me. It is the amniotic fluid, a kind of mother's uterus where there is everything. And if I play the note C? It forms the basis for everything. Of course, this is an eternal truth, that we always keep talking about the light of $\mathrm{C}$, but it also may represent serious light; there is not a lot of edge in C-major. D goes immediately in a more melancholy direction, $\mathrm{E}$ - in a more positive direction, $\mathrm{F}$ is quite cool, $\mathrm{G}$ begins to have some warmth and B looks more smiley.

So, for example, you do not experience the tone $G$ as a colour? No, I feel the warmth in G. Do single tones have their own atmospheres? Absolutely. Certain tones have warmth, coolness or chillness. The tone $\mathrm{G}$ seeks yellowish, for example, the kind of brownish in the autumn forests, $\mathrm{F}$ goes in a cooler direction; it is analytical. A is very logical and B has bubbling warmth. $\mathrm{E}$ is submissive with a little bit of the willow warbler singing, a certain kind of melancholy, even tragedy, and $\mathrm{C}$ is the sum of everything, the progenitrix. What about your experience of the tone F-sharp? It starts to purr towards blue. [I add to the single tone the chord F-sharp minor...] Yes, 
and of course when you take it to B-major it is absolutely logical, this brightness of the major goes hand-in-hand towards the colour violet.

\section{Let's talk more about where the single tones are heading.}

$\mathrm{C}$ is absolute; you can say nothing about it. D gravitates immediately towards the major key and E towards the minor key; A goes rather towards the minor key and B also. I'll ask you again where does $D$ gravitate and what about G? Towards the major key. You are grilling me by design. E-flat leads immediately to a major key while D-sharp leads to minor. F-sharp or G-flat, they are quite close to each other. First, G-flat is the most full-flavoured tone that may be produced from the piano and G-flat is cream-coloured as a sound. What about A-flat or G-sharp? Now there are enormous differences. A-flat is kind of mellow, while G-sharp is incredibly thin, it is a mean tone. A-flat goes towards a major key and G-sharp towards a minor key. B-flat gravitates to major. We are navigating on the polar ice...You are testing me; these are quite constant to me; believe me, there is no bargaining about them.

What about E-major? It is honey-like yellow, a mellow sunset in August. [I play D-flat major chord in different positions.] What is your feeling now? It is a shock...Really? About C-major, I would use the word "beginning light" which has given birth to everything. When we go to D-flat major we move to areas so cold that it is as if we would travel from the warmth of the Garden of Eden to the Antarctic. C-major is a paradisiacal state. It is the most serious major key of all. C-major is not any major or minor key; it is rather something Urtonart - that occurred to me just now, C-major is absolute, it is not a colour, major or minor: it is a light. D-flat, what colour was that or can it be defined? Oh yes, on the other hand it goes rather close to B-flat major; it includes the chilling prisms of eternal ice, but D-flat major is a more intelligent key than B-flat major. It is marvellous and wonderful. Think about Prokofiev's Piano Concerto in D-flat major as it feasts on the arrogant self-assurance, logic; for God's sake, it is not for the humble. It is just crushingly devastating.

If I were to tune a C-major chord so that it would change seamlessly into a D-major chord what would happen to your colour mapping? This is the thing that fascinates me. Now you have arrived at perhaps the most important task we are talking about. Do you know who should be talking with us right now? Liszt, of course. That man knew this business. He had heard things what we can only dream of, but which can be seen in the deep spheres where the meaning of one single tone has led his music. We will never know what he might have heard. For example, in those last Bagatelles without a key he had already gone so far that...If someone were to do a great research and find out what really the truth is behind these concrete chords of Liszt. That forms a new dimension, which we are not able even to imagine. That pianist knew exactly what this is about.

Well, what about D-major? It is somehow interesting, as it is a key with sharp markings. It forms a watershed, as it really belongs to neither; it has some kind of coolness, but it tries to be warmer than it actually is. It includes prisms and is a very difficult key. Does it solidify in any colour to you? It is bluebell blue in colour.

E-flat major is like a humble vassal compared to D-sharp major. In D-sharp major the whole glittering spectrum is blinding. E-flat major is basically a safe classic key, but on the other hand, it is so ruthlessly uninteresting, so bourgeois. The Finale of the Fifth Symphony by Sibelius glows completely in E-flat, regardless of the key it is written in. When we move from there over to D-sharp major, things start happening. What about E-major? It is full of warmth, full summer; if we put honey in the keys, it would be E-major. It is honey-yellow, a mellow August 
evening sunset; it is mere honey. - [In one turning point of our discussion the interviewee noted, for example, that a burning fire is E-major.] If we think about the fire, if you look at the burning candle here, can you tell me if it is in some key for you? Yes, it is in E-major, which is the warmest key, and the fire is definitely in E-major; there is no doubt about that.

If we could go further, what would you say about the key of F-major? It goes more to the cooler side. You could be in F-major mode when you take a snowball in your hand in the late winter when there is a little ice in the bottom, a faint suggestion of blue, a certain feeling; it is very safe. What about the F-sharp major chord. What are your associations? Plenitude, warmth, very warm, safe. F-sharp major and G-flat major; it is very difficult to see the differences. Let's say that it is a caressing, kissing key; definitely the colour goes again to turquoise blue with an enormous sparkling and glitter in both of them. And G-flat major and E-flat minor are the richest and most full-flavoured of the flat keys.

I don't know if there is a sadder key than A-flat minor. Do you mean the atmosphere or the colour? Now I mean the atmosphere; yes of course, A-flat minor goes to something blood acidic, which may partly be the reason that Verdi composed Othello's monologue, which is full of anxiety, in the key of A-flat minor. But if that is so, it means that Verdi has noted this atmosphere. And, by the way, Verdi did notice it.

G-major? It carries the warmth of the early summer, yellowish white. The sun is shining, although the grass has not yet grown. There is the feeling of rich soil in springtime bringing new life, yellowish-whitish brown, incredibly energetic and a strong key. What about A-flat major, then? A flat major goes into something with great warmth somehow combined with a little tenderness; a very beautiful key. The colour definition in A-flat major is quite problematic... [thinks quite a while].. There is somehow warm blue, but if you could combine blue and brown... It is difficult, but if I may say, I know one lady who is clearly in A-flat major.

A-major then? It is bright red. Basically, A-major is cool, intelligent and logical with somehow an edge and a prism. It is not especially warm, yet it is red. And B-flat major?

I already told you, it is quite close to D-flat major; it is arctic. D-flat major is more arrogant than B-flat major. It is immense white and turquoise. In B-flat major there is more humanity, but still they are quite close to each other.

Then B-major? We are moving back towards warmth, pretty close to E-major. B-major is kind of fresh and bright green, a forest view where the golden sun is shining. I am continuously becoming conscious of these different keys in music. It is a good thing that you have motivated me to talk about them. When I was jogging one evening and looked at the setting sun shining in the pine trees, certain keys started cruising around in my head, from the deepest green of B-major to the tastiest honey of E-major, but all this was part of nature to me. This is how it goes. It is my life and I don't have to think about the colours; they already are inside me. I live in them.

\section{The minor keys are softer than the major ones}

Does the shade of the colour change if we talk about minor keys?

Minor keys are softer. C-minor is black and white. What do you mean by that? It means classicism to me. It is not connected to the piano keyboard with ebony and ivory; it means that in classicism, black and white are somehow not real colours, although some painter might argue differently. In C-minor two non coloured, but still colourful components are joined together, if I can describe it like that.

C-minor, E-flat major and C-major are extremely objective, the clearest classical keys; 
you can only kneel before them. The keys of C-major and C-minor are so rugged. They are the sum of all colours, the sum of everything. Only geniuses can compose in these keys. There have been two geniuses: Beethoven and Mozart. No others - and there will not be any others. To them these keys were like a fan grown from a mustard seed into a big tree, which connects everything. It is useless for others to try. This has already been said and done.

\section{happy}

If someone were to play music only in C-sharp minor at my funeral, I would be really

What about D-flat minor or C-sharp minor?

$\mathrm{C}$-sharp minor is homely and safe. It is the beginning of the Moonlight Sonata. Think what would happen if the Moonlight Sonata were written enharmonically in the key of D-flat minor; what state of dissolution that would be. It would lead to horrible atmospheres. May the Lord Almighty protect us from D-flat minor. It is hostile and carries evil forces. It may be the most horrifying thing I can think of at this very moment. If you take the C-sharp minor chord, there is nothing sweeter; in that chord I would someday like to go beyond time, to die beautifully. If someone were to play music only in C-sharp minor at my funeral, I would be really happy. It caresses like velvet. You have to be sharp with colours; it goes somewhere into the purple of gold. That is it. Is it so? Has anyone ever composed in D-flat minor? I don't know. Probably not. I am feeling chilled.

But C-sharp minor is totally different! It is gentle, it is wise, it is very mature, and it is a pretty, motherly key, which has given birth to many children, maybe even several keys, too. It has a sense of humour, and it is mellow like A-flat major, about C-sharp minor you can say that it leads into more golden green than her sister B-major, and they both have the wisdom of August in them. A-flat major also has a lot of the warmth of the month of August.

\section{D-minor is the tragic key}

D-minor? Now we are in such a blue-greyish minor key. It is the key of tragedy, yet not as much as G-minor. G-minor is the key of death; well, I would say that D-minor is like December. You say that G-minor is the key of death; why? Can you explain why you experience it like that? Yes, I can. I absolutely can. You just explore the production of great masters, from Mozart to French popular music such as Autumn leaves. When death is the focus, the music is always in the key of G-minor. Pamina sings in G-minor in The Magic flute, but we can also find this in Autumn leaves. It cannot be just accidental, because so many composers write their suspicions of death in this key. D-minor is principally the kind of key that is torn by pain, but G-minor wins. It still has more shades of death.

\section{$G$-minor is the key of human life dying}

G-minor is the key of the colours of autumn, of rotting and decomposing leaves, the key of everything that turns into dust and humus. D-minor and G-minor are side by side. The Dies Irae of Verdi's Requiem is in D-minor, but when you are face to face with death, it is G-minor, the key of human life dying. It is the key of the greatest pain in the whole world. And what would be the opposite? On the objective level, if a human being has ascended high enough, which seldom happens - it is to the key of C-major. What colour does G-minor represent to you? I have already told you many times...Go to a forest in October; it is golden brown and yellowish, the key of sorrow. If I play, for example, a G-minor chord, how do you feel it as a colour? It is the colour of decomposing leaves... it is the key of death; if a month were to be put into the key of G-minor, it would be October.

What about E-flat minor? A key of terrible longing and it goes to deepest sepia brown. 
It is the key of despair, and if E-flat minor becomes the colour of a person, it is a pity. That poor person has a horrifying, endlessly deep sepia brown misery, a key that is the colour of misfortune. The person, who feels the key of E-flat minor within has done something terribly wrong, committed a grave sin. Could you possibly name some people with that colour? [A long silence...] Would you like to say? Yes, I would. That was such a good question that I want to answer it. Yesterday I was watching Mirjam Helin song contest, and there was a very nice SouthAfrican singer (a boy) singing Sibelius' song Flickan kom från sin alsklings möte. I followed his work, and noticed that this exotic, dark, rough-looking singer carried E-flat minor inside. The Goddess Hera had the pain of E-flat minor, the knowledge and the depth.

What about E-minor, which you were talking about a little earlier? It is lighter, more lyrical and elegiac, like the song of a willow warbler. I cannot say that the willow warbler would be a nerd, but the key does not have carrying power. And F-sharp minor? It is purple, wise and mature; it is so purple that an artist finds it difficult to reproduce such a colour. How do you mean purple? It is lilac. It is violet, but much more dramatic.

G-sharp minor? It is you! It is a kind of rich people's key -although you don't have any money - one of the most exotic keys. You are G-sharp minor. Why? It is true, dear Heikki. G-sharp minor has a strange tension; let's say that there is something smouldering under the skin, and it is the spitting image of you. There is a kind of sad brilliancy or glamorously glittering sadness. Can you explain why you see it this way? Yes, I can. I can and I will tell you that right away. You are exactly G-sharp minor, which is a mysterious key. Someone could say that it is A-flat minor, and that is even more mysterious. A-flat minor is a key of destruction, which G-sharp minor is not. G-sharp minor has to do with your colourfulness and your personality, both of which have a lot of the stimulating energy of empathy, delight and joy as well as a strong melancholy undertone. At the same time a flowing spring mingles with the autumn like the colouring of human nature - don't take this the wrong way - which tells about maturity and a life lived. It is richness. It is knowledge gained through experiences in life: remember that after the autumn, there always follows a new spring, new life. You are definitely G-sharp minor to me. This was a good thing to ask; I did not have to think long about it.

\section{A-minor is the flower of the arctic bramble}

A-minor key, the colour? I disagree with the composer Heikki Klemetti. I would say that the flower of "Luhurikka", the arctic bramble, is the key of minor. The colour is a gentle redviolet. The most perfect A-minor I can name is the flower of the arctic bramble. When Klemetti talked about this flower, for him it was flowering in E-minor, for me it is definitely this aniline A-minor. But the fact that Klemetti had these associations, does not mean that any of them were absolute truth or factual; I think that we don't have so many people today who even think about these things in music. Klemetti talked nicely, saying, "The elegiac flower of the arctic bramble is E-minor", which sounds great, except that for me it is A-minor.

What do you say about B-flat minor? It is a tragic, deeply clinging-to-your-guts key. We are going into as deep a blue as there can be. It is the deepest blue I know, indigo or even deeper than that, it is the blue of night. Tell me, what key are you in? B-flat minor. When I started thinking about these things, my key has been B-minor ever since. That is why I am so addicted to indigo blue. I remember when I was a kid and my father was a police officer; I always admired that blue uniform. I did not analyze it in any way; I just knew that the colour attracted me a lot. When father came home, he immediately changed into normal civil clothing. That's when I asked him: why do you change clothes when the colour is so beautiful? 
How do you experience B-minor? It follows the blue line, but clearly much more gently. It is blue with a little greyish; it is a gentle blue colour. I just started thinking as I tried to remember things, and suddenly it occurred to me that I am getting into the sources of this whole thing. It has been the Tchaikovsky's Pathétique Symphony that started this all. That desperate B-minor that is in it - not knowing my own identity in those days I identified myself in Tchaikovsky's music, and that's where I started to see almost a dark, blue-green B-minor key. I felt the pain of the world, and that is where it started; it brought out the colours for the first time. We lived in Hietalahdenkatu [Vaasa, Finland], and I was standing beside Westerlund's music store, and it was raining, a warm rain.

\section{A birch goes pretty much in F-major and that spruce over there is B-major}

E-major is the key of pine trees, but the pine forest may also be in E-flat major (Sibelius's Finale of the Fifth Symphony sounds like this forest). B-major is the spruce trees. I want to stop for a while. Could you rationalize a little bit? Well, it just is so, I can't help it. A birch? Goes pretty much in F-major. A rowan? This is coming a little fast, now I have to think. A rowan could even be A-flat major. I am thinking about G-sharp major (the colour and the bitter taste of the rowan berries). I have to think about this. Are there trees suggest an association quickly? The birch, the pine, the spruce and the willow do. Willow goes into an elegiac E-minor key, an alder is A-minor, the hagberry is B-minor, and the oak is E-flat major. A maple tree? It is difficult, it goes somewhere around the keys of E-major, C-sharp minor, G-sharp minor or somewhere in that area. I do not have an answer for the maple tree; it is difficult.

Can you explain what makes some trees difficult? Why would some trees be easier to connect with keys than others? The oak is quite classical; it is a strong and very objective tree. It is a little like Beethoven's Eroica, a heroic tree. Then if we consider a melancholy alder growing by a lake, it is quite different. A birch has energy; it is a little bit of a cool tree with some light in it, and that is why F-major suits it well. A willow mournfully growing by the edge of a ditch makes an elegiac E-minor as we said - the willow warbler's singing goes in E-minor.

Sometimes late in the autumn a maple tree might be in G-sharp minor if it gets the right coloration. Yesterday we discussed a pine tree being in E-major, and a birch being in F-major and a willow being in E-minor key. It is difficult to talk about these, because to me they are self-evident. It is like another nature to me; now I see that I am living all the time inside this mess. I have colours and music all the time. I walk around in such a world, but this is the first time I have ever talked about it. That is why I hope that I am able to express these things. That spruce over there is in B-major and that fountain over there is bubbling in a nice F-major. Is that so? Of course it is.

\section{A willow warbler, an elegiac E-minor}

About the birds? A chaffinch is in E-flat major, an energetic, very analytical key, clear and not at all bleary. A willow warbler is an elegiac E-minor. Maybe one of the most gentle and melancholy birds singing in Finland. It is like the piano concerto by Chopin in E-minor, the "willow warbler concerto". Then there is the garden warbler. A glittering and gloriously twittering G-flat major. Then we move over to those... the song thrush, which modulates so much that you cannot say anything about it. Then the jubilant swallow, which makes it B-major. Ask me about another kind of bird. A crow? I can't help it: it brings to my mind Schubert's Die Krähe, D-minor. Well, what about the seagulls, then? They are atonal. The habitus of a crow is depressingly black and grey, exactly like D-minor. A crow is absolutely in the key of D-minor. 


\section{Absolute music does not produce colours}

[I play Bach's two part Invention in A-minor]. What kind of atmosphere or colour does this suggest to you? An excellent question. Bach already goes into the category of "das Ding an sich"; oh my, that is a good question. I don't mean this Invention or the slow part of the Italian Concerto...they don't produce any colours as they are so deeply absolute music somehow. It is music which...I have never thought about this...let's say in the same way as this F-major in the beginning of this [plays the piano], it does not produce any colours. For me it is music, it is absolute music, and maybe Bach's absolute music does not suggest any other associations except pure music. Are there other similar composers? Mozart, for example? Mozart is pretty much the same as Bach in that light. The colours come, let's say, with the romantic era, not to mention impressionist music. Beethoven might... let's say the next to last sonata; yes, it is a colour sonata, but not Bach, that is true.

Does it rather go through the orchestral music? If I invent these kinds of chords [playing them on the piano], do you experience any kind of colour? Yes, I did. And it has to do with these chords? It does. I saw a certain kind of horizon, and it had gentle grey, yellow, a little bit of aniline-red, but they get mixed together somehow. No it started immediately; I saw the colours starting with the first chord on piano.

\section{About people and keys}

Do you sense some people in some keys? How strong are these experiences? Does it have something to do with knowing the people? No, it has nothing to do with knowing the people. Sometimes I get such a strong experience from seeing a person while riding my bicycle that I almost fall down, and it has nothing to do with the physical or sexual beauty of the person. It may be a lady going to the store. It has something to do with the colours she is wearing - a humble old lady - being in such perfect harmony both with the whole colouring and the style of her clothing, and not even noticing it herself. My eyes just rest in looking at her, the perfect harmony, and maybe because of it she was reflecting an inner peace. Did you recognize any key in the experience? Well, yes it goes in D-minor, which is the most philosophical and thoughtful, tranquil, and maybe one of the most peaceful of all keys. It is also quite close to the death key. There are many Requiems written in D-minor; G-minor is even closer to death.

Why do you feel yourself being in the key of B-flat minor? Why not, for example in $B$-minor or A-minor? Of course I have been thinking about that, and it is easy to answer. I never could be in those other keys. Why couldn't you be in C-minor? It is because I am not such a black and white person; C-minor might be for some great guru, but the deep presence of destiny in B-flat minor and some sort of drama, some kind of mysticism...

What about Sibelius, how do you experience his music, or Beethoven's? Well, yes, I do experience something with them. To me personally, relatively young Sibelius is closest. Just the Sibelius who wrote the Romance in A-major, Kullervo, and works in which his picture is the forest-Sibelius, the trailblazer of Finnish primeval forests, who dives into the same waters with his music as Aleksis Kivi did in using the Finnish language. The minor key dominates and it dives into rich minor keys that are close to nature, into D-minor and even into major keys which sound as if they are in minor. The Violin Concerto is in D-minor, which is one of the most beautiful compositions by Sibelius as well as the string quartet Voces intimae. Beethoven is an absolute classic who raises above colours, which means that he is black and white, meaning C-major, $\mathrm{C}$-minor, E-flat major. Pure classicism is black and white. These are no longer colours. And it 
is so crystal clear and absolute that where the colours end, that is just the point at which they begin.

\section{The emotional sensations}

Let's talk about emotions. If I say the word anxiety, for example, could it be simplified to some chord or key or colour? If a person has a great deal of anxiety, is there some concrete similarity that you could sense in tones, music or colours? Oh yes, it can be done, it is very a dark F-sharp minor key which goes to extreme points of violet-lilac. F-sharp minor is heart gripping and harrowing, one of the most anxious keys you could ever imagine. Also in Tchaikovsky's Pathétique Symphony B-minor goes deep into the mud finding the deepest and muddiest feelings of anxiety. They can be found there. Verdi too observed this human anxiety, maybe the most ingeniously of all. The Othello's monologue is in A-flat minor, a key seldom used by Verdi, but it conveys the shocking jealousy, the self-serving; which is perhaps the most anxious ever heard in music. It goes to the depths; very few composers have used the key of A-flat minor.

What about G-sharp minor? It is not one of the tragic minor keys. It is one of the most colourful ones, like you, who are a G-sharp minor person. But it is not tragic; it has enormous potential. No one has ever composed s G-sharp minor concerto or symphony because the key is frightening. I wonder what the reason is for the lack of concertos with many sharps or flats in the key signature. When we think about it, we easily see that they usually stop at four sharps or four flats. It is a shame, because lots of colours are lost! It would be interesting, as there would be caressing, like the key of E-flat caresses in just a certain way, but if it would turn into D-sharp major, it would be even more tender, like a summer morning's concerto.

Peace, tranquillity, joy and happiness are immediately connected with a key. Is it too banal to connect certain keys to certain emotions? No, on the contrary it is a good question and easy to answer. All the emotions mentioned have their own keys. Ask me more; this is easy for me. Tell me then, what is the key of peace? It can be found both in minor and in major keys. C-sharp minor and D-minor are very peaceful, but also there are two major keys, A-flat major and the source of crystal clear peace, G-flat major. In D-minor there is kind of melancholy, deep philosophical peace, mature. C-sharp minor is a mature human being's autumn, which outlines life's borders with its pen. Then if we immediately move to A-flat major, it is warm, even warmer than G-flat major. That's it.

Joy, happiness, victory? We are moving to glittering keys. There is B-major, the sharp keys glitter more beautifully than the flat ones. They have more warmth. I see B-major as a marvellous key of joy. Maybe also C-major, but as I said, it is the kind of key that is not a real key. I don't count it as such; still I think about Beethoven's Fidelio: it is spiritualized joy, deeply spiritual euphoria. B-major, of course, and B-flat major too, but there is certain feeling of calculations, a kind of artificial joy, because it is a quite technical key.

What about sorrow, bereavement, disappearance? If we go into the deepest sorrow and feel it thoroughly, it becomes C-major, a key that is not really a key at all. In the deepest sorrow it is unnecessary to seek piercing minor keys. It no longer has anything to do with B-minor or B-flat minor, as the sorrow has already crystallized, and the human being's ability to feel it and stand it, possibly gets over it, brings us to C-major as in Orpheus 's tragic C-major by Gluck.

\section{RESULTS AND CONCLUSIONS}

\section{Analysis and interpretation of the interview, and some conclusions}

Experiencing musical compositions in colours is a very individual matter. The colour associations often differ from one synaesthetic person to another (van Campen, 1997; Rogers, 
1987). In the literature there are references to the synaesthesia of composers such as Oliver Messiaen, Nikolai Rimsky-Korsakov, Franz Liszt and Jean Sibelius. The interviewee disagreed strongly, for example, with Alexander Skrjabin's colour palette, as the discussions clearly showed: "I strongly disagree, that Skrjabin composed some sort of colour symphony. I believe there was nothing in it about which I would have thought the same way. I do not mean at all that Skrjabin was wrong. He constructed a kind of colour organ. It was played in Finlandia hall in Helsinki. I felt physically sick when I realized that everything was totally different compared to my own thoughts end experiences. I don't think that I am any kind of guru, but I have my own colour palette and Skrjabin had his. Surely neither of us is absolutely right." The interviewee also speculated about composers who have had synaesthesia experiences with colour. "Among others, Verdi, Liszt, Richard Strauss knew the idea. When you realize that some of these composers knew about this experience, it is like we used to say in this part of Finland, life is as good as it can be. The music opens up so that I know it has to be exactly as it is". In this case study the interviewer in the beginning tried to see the interviewee's colour world as being simpler than it actually is. The interviewee does not always see colours when listening to music. He also experiences the colours in different keys, which is quite rare according to the literature on synaesthesia. The synaesthetic experience is often a one-way business: for example, a taste brings up a tone, but a tone does not synaesthetically bring up the taste (Day, 1996; Ione \& Tyler, 2004). "The key of this wall is a lurid E-major" as the interviewee stated. They are like absolute experiences for you? "Oh yes, they are absolute experiences and sometimes so brilliant that I believe I am alone with these experiences." The interviewee experiences synaesthesia spontaneously, which fulfils the first of Cytowic's principles.

The colours of minor keys show up in the interviewee's world as being softer than those of major keys. He also feels that the major key includes more minor than the minor key does major. At its deepest, the major key also includes the minor key. The minor key is not as strong as the major. Single tones do not necessarily produce colour experiences, but the single tones have a tendency to seek their way to certain keys. $\mathrm{C}$ as a single tone is simultaneously everything and nothing, and it seeks its way either to a major or a minor key. The interviewee experiences all tones the same way. Moreover the colourings of musical compositions have not changed as the years have passed. The single tones have their own atmospheres which the interviewee describes with such concepts as "warmth, coolness, coldness". The colours do not change with an octave change, they simply deepen or lighten. The colour of the same chord does not change when there is a change of octave, but the brightness of the colour does change. It correlates exactly with the register of piano keyboard. The interviewee also noted that the colours fade as the resolution power disappears. The colour becomes thinner in the discant and in the bass. According to Day (1999), half of the population perceive higher tones as brighter and lower tones as darker. These experiences indicate that synaesthetic experiences have remained similar through the years, which shows that they are permanent and not the products of a vivid visual imagination. Thus Cytowic's second and third principles are fulfilled.

For the interviewee the colours in major key are not necessarily bright and those of minor are not dim; they may also occur in quite the opposite way. If the same tone is tuned up a little higher, the colour stays the same, but the brightness changes. If a chord is played in the same octave, but with a different instrument, the colour stays the same (with the chord). Flat keys on the whole are colder than the sharp keys. Enharmonic keys are two different things for him. In discussion it often happened that it was difficult to describe the acoustic-visual world 
experienced by the interviewee using words only.

The colours of different keys have remained the same for the interviewee throughout his life; he became conscious of them in adolescence just before entering adulthood. The association between colours and tones did not have any effect on his musical learning or playing an instrument. He still practices piano for days at a time, without thinking about colour associations. The colour associations were more closely connected with a chord or with homophonic characteristics, for example, than with polyphonic music. They were most pure in harmonies, triads or even in single tones.

Although the interviewee experiences the colour associations as absolute, their linguistic manifestation takes place on many levels. It is even in quite metaphorical speech, which may connect experiences from different sense areas. In this way a synaesthetic experience appears multidimensional, for example, mixing visual experiences with aural ones (trees and people are heard in different keys). During earlier discussions with the interviewee, it became clear that he is an absolutely synaesthetic individual (Harrison \& Baron-Cohen, 1994, 343), for whom synaesthetic experiences are a real and permanent phenomenon in his life. Synaesthesia can be seen more widely as a general ability to describe one sense with another (Korb, 1995, 2). In this way too Cytowic's last two principles are fulfilled.

The interpretation of synaesthesia for this individual is that the colour associations are mostly independent of will, and they take place automatically as absolute phenomena. The strength of a synaesthetic experience remained open in the interview; it was not defined in any way. The question of whether some keys generate clearer associations than others also remained unanswered. Some researchers (Harrison \& Baron-Cohen, 1994) have found clear signs of graduated blood-streaming in a synaesthetic person's brain where neurologic sense connections from different auditory stimulae should not be taking place. Also the permanency, the logic of the experiences, as well as the testing of the interviewee through questioning promotes the idea of authentic synaesthesia case. The description of a synaesthetic experience finds metaphorical expression. The reliability of this case study has been strengthened by the interviewee's reading and accepting this article after some corrections were made.

This study raises many questions. It would be interesting to know the circumstances in which absolute colour associations are born. (Kadosh et al., 2009) What is their neurophysiological (Rouw \& Scholte, 2010; Weiss \& Flinck, 2009; Bargary \& Mitchell, 2008; Hochel \& Milán, 2008; Simner, 2007) basis? Why have composers selected certain keys for certain compositions? What would be the complementary key possibilities during the composing process, and are colour associations, brightness, the lightness or warmth of the tones subconsciously connected with the choice of key? How conscious is the choice of key in the composing process? How would the world of the interviewee look to a psychoanalyst? Does a sound cause an emotion and does the emotion cause the synaesthetic experience? Could the synaesthetic experience and sense integration be opposite poles of the same phenomenon? With what words and concepts is music usually expressed? Or could the truth be seen in the words of the interviewee, who said: "the most ingenious compositions go towards the absolute truth, into such big ideas that the colours stand aside; it is pure and crystallized brightness, which shows that the colours are merely the instruments for getting there." 


\section{REFERENCES}

Bargary, G., \& Mitchell, K. (2008). Synaesthesia and cortical connectivity. Trends Neurosci, 31, 335-342.

Barnett, K., \& Newell, F. (2008). Synaesthesia is associated with enhanced, self-rated visual imagery. Consciousness and Cognition 17(3), 1032-1039.

Barnett, K., Finucane, C., Asher, J., Bargary, G., Corvin, A., Newell, F., \& Mitchell, K. (2008). Familial patterns and the origins of individual differences in synaesthesia. Cognition, 106(2), 871-893.

Baron-Cohen, S., Harrison, J. E., Goldstein, L. H., \& Wyke, M. (1994). Coloured speech perception: Is synaesthesia what happens when modularity breaks down? Perception, 22, 419-426.

Baudelaire, C. (1860). Correspondences, poem originally. In Les Fleurs du Mal [Flowers of evil]. Retrieved February 22, 2011, from http://baudelaire.litteratura.com/les_fleurs_du_mal.php.

Beeli, G., Esslen, M., \& Jäncke, L. (2008). Time course of neural activity correlated with coloured-hearing synaesthesia. Cerebral Cortex, 18(2), 379-385.

Cammack, J. (1999). Synaesthesia and knowing. The fights international workshop on the cognitive science of natural language processing. Language, vision and music. National University of Ireland, Information Technology Center, pp.158-165.

Van Campen, C. (1997). Synaesthesia and artistic experimentation. Psyche, 3(6). Retrieved October 10, 2000, from http://psyche.cis.monash.etu.au/v3/psyche-3-06-vancampen.html.

Van Campen, C. (2010). The hidden sense. synaesthesia in art and science. The MIT Press, UItgeverij Zien, Cantecleer. Retrieved February 22, 2011, from http://www.pucsp.br/.

Cytowic, R. (1995). Synaesthesia: phenomenology and neuropsychology. A review of current knowledge. Psyche, 2(10). Retrieved October 2, 2000, from http://psyche.cis.monash.etu.au/.

Cytowic, R. (1997). Synaesthesia: phenomenology and neuropsychology. A review of current knowledge. In Baron-Cohen, S. \& Harrison, J. (Eds.), Synaesthesia: Classic and contemporary readings. Oxford: Blackwell Publicers Ltd.

Cytowic, R. (1989/2002). Synaesthesia: A union of the senses. New York: Springer-Verlag.

Cytowic, R. (2003). The man who tastes shapes. Cambridge: MIT Press Edition.

Cytowic, R. \& Eagleman, D. (2009). Wednesday is indigo blue. Cambridge: the MIT Press.

Day, S. (1996). Synaesthesia and synaesthetic metaphors. Psyche, 2(32), 1-16. Retrieved October 10, 2000, from http://psyche.cis.monash.etu.au/.

Day, S. (1999). What synaesthesia is. The fights international workshop on the cognitive science of natural language processing them. Language, vision and music. National University of Ireland, Information Technology Center, pp.178-185.

Galton, F. (1880). Visualized numerals, Nature 21, 252-256.

Gray, J., Chopping, S., Nunn, J., Parslow, D., Gregory, L., Williams, S., Brammer, M. \& Baron-Cohen, S. (2002). Implications of synaesthesia for functionalism: Theory and experiments. Journal of Consciousness Studies, 9(12), 5-31.

Harrison, J. \& Baron-Cohen, S. (1994). Synaesthesia: An account of coloured hearing. Leonardo, 27(4), 343346.

Hochel, M. \& Milán, E. (2008). Synaesthesia: The existing state of affairs. Cognitive Neuropsychology, 25, 93-117. 
Hubbard, E. M., Manohar, S., Ramachandran, V. S. (2006). Contrast affects the strength of synaesthetic colours. Cortex, 42(2), 184-194.

Hubbard, E. M. \& Ramachandran, V. A. (2005). Neurocognitive mechanisms of synaesthesia. Neuron, 48, 509520 .

Ione, A. \& Tyler, C. (2004) Neuroscience, history and the arts. Synaesthesia: Is F-sharp coloured violet? Journal of the History of the Neurosciences, 13(1), 58-65.

Kadosh, R., Henik, A. \& Walsh, V. (2009). Synaesthesia: Learned or lost? Developmental Science, 12(3), 484 491.

Nunn, J. A., Gregory, L. J., Brammer, M., Williams, S. C. R., Parslow, D. M., Morgan, M. J., Morris, R. G., Bullmore, E. T. Baron- Cohen, S. \& Gray, J. A. (2002). Functional magnetic resonance imaging of synaesthesia: Activation of V4/V8 by spoken words. Nature Neuroscience, 5, 371-375.

Palolahti, M. (2007). Sininen ääni, laulava liike, ruusuntuoksuinen kosketus: Synestesia ja kokeellinen kognitiontutkimus [Blue note, singing movement, rose smelling touch: Synaesthesia and empiric cognition science]. Homunculus, 1, Retrieved April 16, 2010, from http://blogit.helsinki.fi/ homunculus/2007-synestesia.htm.

Ramachandran, V. A. \& Hubbard, E. M. (2001a). Psychophysical investigations into the neural basis of synaesthesia. Proceedings of the Royal Society of London, 268, 979-983.

Ramachandran, V. A. \& Hubbard, E. M. (2001b). Synaesthesia: A window into perception, thought and language. Journal of Consciousness Studies, 10, 49-57.

Ramachandran, V. A. \& Hubbard, E. M. (2003). Hearing colors, tasting shapes. Scientific American, 288(5), $52-9$.

Rogers, G. L. (1987). For case of pitch-specific chromestesia in trained musicansa with absolute pitch. Psychology of Music, 15(2), 198-207.

Rouw, R. \& Scholte, H. (2010). Neural basis of individual differences in synaesthetic experiences. The Journal of Neuroscience, 5, 30(18), 6205-6213.

Schmidt, G. L., DeBuse, C. J. \& Seger, C. A. (2006). Right hemisphere metaphor processing? Characterizing the lateralization of semantic processes. Brain \& Language, 100(2), 127-141.

Segal, G. (1997). Synaesthesia: Implications for modularity of mind. In Teoksessa Baron-Cohen \& Harrison (Eds.), Synaesthesia: Classic and contemporary readings. Oxford: Blackwell Publishers.

Simner, J. (2007). Beyond perception: Synaesthesia as a psycholinguistic phenomenon. Trends Cogn Sci 11, $23-29$.

Smilek, D., Dixon, M. J., Cudahy, C., \& Merikle, P. (2002). Synaesthetic colour experiences influence memory. Psychological Science, 13, 6 .

Smilek, D. \& Dixon, M. J. (2002). Towards a synergistic understanding of synaesthesia: Combining current experimental findings with synaesthetes' subjective descriptions. Psyche, $8(01)$. Retrieved February 23, 2011, from http://psyche.cs.monash.edu.au/v8/psyche-8-01-smilek.html.

Ward, J., Thomson-Lake, D., Ely, R. \& Kaminski, F. (2008). Synaesthesia, creativity and art: What is the link? British Journal of Psychology, 99(1), 127-41.

Ward, J. \& Mattingley, J. B. (2006). Synaesthesia: an overview of contemporary findings and controversies. Cortex, 42(2), 129-136.

Weiss, P. \& Fink, G. (2009). Grapheme-colour synaesthetes show increased grey matter volumes of parietal and fusiform cortex. Brain, 132, 65-70. 